\title{
EFFECT OF FINES ON LIQUEFACTION USING SHAKE TABLE TEST
}

\author{
S. R. Pathak ${ }^{1}$, Madhura Joshi' ${ }^{2}$, Mugdha Kshirsagar ${ }^{3}$ \\ ${ }^{1}$ Professor, Department of Civil Engineering, College of Engineering, Pune, India. \\ ${ }^{2}$ Assistant Professor, Department of Civil Engineering, Sinhagad Acadamy of Engineering, Pune, India. \\ ${ }^{3}$ Assistant Professor, Department of Civil Engineering, Symbiosis Institute of Technology, Symbiosis International \\ University (SIU), Lavale Pune, India.
}

\begin{abstract}
Earthquake is one of the most disastrous natural calamities resulting into considerable damages. One of the most detrimental effects caused due to earthquake is liquefaction. This paper deals with experimental investigation of effects of fines content on liquefaction behavior using shake table test. A test program consisted of total 19 tests conducted on saturated cohesionless sand with varying amount of non-plastic silt. The behavior of such silty sand in the relative density range 30 to $60 \%$ has been studied by subjecting the specimens to a specific acceleration of $0.54 \mathrm{~g}$. Effect of silt content and the relative density on generation of pore pressure and thereby initiation of liquefaction has been studied. The results obtained from the present study showed that cyclic stress ratio (CSR) values decrease with the increase in fines content for lower relative densities. Delay in development of pore pressure is observed with the increasing fines content. This indicates that higher silt contents at higher densities offer better resistance to liquefaction. Further, for lower densities and lesser silt contents liquefaction occurred at pore pressure ratio even less than one. The trend observed for CSR and relative density is similar when compared with triaxial test reported in literature. The points where liquefaction has occurred in the field, when checked in the present study, they lie in 'YES' zone of liquefaction.
\end{abstract}

Keywords: Relative Density, Cyclic Stress Ratio, Pore Pressure Ratio, Liquefaction Resistance, Initiation of Liquefaction

\section{INTRODUCTION}

Seismically induced liquefaction has long been recognized as a phenomenon causing serious damage to foundations and structures resting on saturated sandy soils. Earlier studies showed that clean sand having uniform gradation undergo this phenomenon. However, since 1960's it has been observed that the presence of silt and clay particles in some way or other affects the liquefaction resistance of sand under cyclic loading. The role of non-plastic or plastic silt on liquefaction behavior has been a topic of debate. A review of literature shows that there are no clear consequences of effect of non-plastic silt upon the liquefaction resistance of sand. Various laboratory and field studies have been carried out to find out the liquefaction behavior of the silty sand. The present paper deals with the experimental work carried out to study the effects of fines on earthquake induced liquefaction using shake table test. The shake table test well simulates the field conditions in the laboratory. To study the liquefaction behavior of the sand silt mixture, the other parameters used in this study are cyclic stress ratio (CSR), pore pressure, pore pressure ratio $\left(r_{u}\right)$.

\section{LITERATURE REVIEW}

The role of non-plastic silt on the liquefaction behavior of sands has been a topic of debate for some time. Polito and Martin (2001) carried out a study regarding effects of fines on liquefaction resistance using cyclic triaxial test with silt content varying from 0 to $100 \%$.Cyclic resistance is considered to be a measure of ability of soil to resist liquefaction. The concept of limiting silt content was put forward by Polito (1999) and the effect of silt content on various parameters was studied in terms of limiting silt content in this work. Findings from his study concluded that silty sand's behavior cannot be accurately predicted based solely on silt content. Prasad et al (2004) have developed a manual shake table using laminar box. However, it does not take into account payload and the criterion for initiation of liquefaction in terms of CSR. Behra et al (2005) studied liquefaction behavior of silty sand by conducting shake table tests on samples with different silt contents. The work focused mainly on resistance offered by silty sand to liquefaction for steady state of vibrations, which concludes that with the increasing silt percentage, number of cycles required for initiation of liquefaction goes on increasing. Zhou \& Chen (2007) conducted undrained triaxial tests and obtained the correlation between liquefaction resistance and shear wave velocity $\left(\mathrm{V}_{\mathrm{S}}\right)$. The developed correlation is further converted to equivalent field conditions, which shows variation of cyclic resistance ratio with shear wave velocity. Work carried out by Ningliu and Mitchell (2006) is based on the study of false positives (No liquefaction detected when the normalized shear wave velocity-cyclic stress ratio $\left(\mathrm{V}_{\mathrm{S}}-\mathrm{CSR}\right)$ combination indicated that it should have been) that are observed in shear wave velocity based approach. Authors established a new modified theoretical cyclic resistance ratio $\left(\mathrm{CRR}_{\text {field }}\right)$ versus $\mathrm{V}_{\mathrm{S}}$ curves for silty sands containing 0 to $15 \%$ nonplastic fines; further observed that fines content affects CRR values considerably. Iwasaki and Tatsuoka (1997) have reported that the small-strain shear modulus $\mathrm{G}_{0}$, and therefore $\mathrm{V}_{\mathrm{s}}$, decrease rapidly with 
increase in nonplastic fines content. Carraro et al. (2003) conducted a series of 64 undrained cyclic triaxial tests on reconstituted specimens of Ottawa sand for determination of CRRtriaxial with fines content varying from 0 to $15 \%$. It was observed that CSR decreases with increase in silt content from 0 to $15 \%$. The boundary curves between liquefaction and no liquefaction zones from Andrus et.al (2003) are shown for fines less than 5\% and less than 15\% and also included false positives for sands having fines 6 to $15 \%$. Thus, it was inferred that liquefaction assessment based on shear wave velocity may be reliable for clean sands, but for sand containing fines, over conservative results may occur. Singh et al (2008) presented the liquefaction behavior of the Solani sand by performing shake table tests at varying acceleration with constant frequency. The results were interpreted in terms of the pore water pressure and the time elapsed during various stages. It was observed that there was little effect of level of acceleration on the magnitude of maximum pore water pressure; however time required in reaching the peak value decreased at higher acceleration.

Thus, an extensive literature survey reveals that not only the clean sand but sand with some amount of fines also undergoes liquefaction. However, no clear conclusions have been reported so far about the liquefaction resistance offered by silty sand. The authors of this paper have made an attempt to investigate effect of non-plastic fines on initiation of liquefaction using laboratory test. As shake table test could more closely simulate the ground motion during earthquake, a series of tests have been performed on sandsilt mixture of different relative densities with varying amount of silt for a particular acceleration, frequency and amplitude of shaking.

Table 1 Properties of clean Sand

\begin{tabular}{|c|c|c|}
\hline Property & Value & IS-Code \\
\hline$\gamma_{\max }$ & $17.44 \mathrm{KN} / \mathrm{m}^{3}$ & IS :2770 (Part 14) - 1983 \\
\hline$\gamma_{\min }$ & $15.06 \mathrm{KN} / \mathrm{m}^{3}$ & IS :2770 (Part 14) - 1983 \\
\hline$G$ & 2.6582 & IS :2770 (Part 3/ Sec1) - 1980 \\
\hline$e_{\max }$ & 0.7641 & IS :2770 (Part 14) - 1983 \\
\hline$e_{\min }$ & 0.524 & IS :2770 (Part 14) - 1983 \\
\hline$D_{50}$ & $0.30 \mathrm{~mm}$ & IS :2770 (Part 4) - 1985 \\
\hline$D_{60}$ & $0.32 \mathrm{~mm}$ & IS :2770 (Part 4) - 1985 \\
\hline$D_{10}$ & $0.175 \mathrm{~mm}$ & IS :2770 (Part 4) - 1985 \\
\hline$D_{30}$ & 0.24 & IS :2770 (Part 4) - 1985 \\
\hline$C_{U}$ & 1.71 & IS :2770 (Part 4) - 1985 \\
\hline$C_{C}$ & 1.02 & IS :2770 (Part 4) - 1985 \\
\hline
\end{tabular}

\section{EXPERIMENTAL INVESTIGATIONS}

Total 19 tests were conducted on silty sand for silt contents of $5 \%, 10 \%, 15 \% \& 20 \%$ with relative densities of $30 \%$, $40 \%, 50 \%$ \& $60 \%$, the variation is based on the field variables available from literature review The 3 tests were performed with field data. All tests are performed by shaking the specimens for maximum acceleration of $0.54 \mathrm{~g}$. Properties of uniformly graded sand selected for the present work are as shown in table 1 . The specific gravity of silt is 2.942. A typical gradation curve for clean sand and sand + $5 \%$ silt has been depicted in the Figure 1.

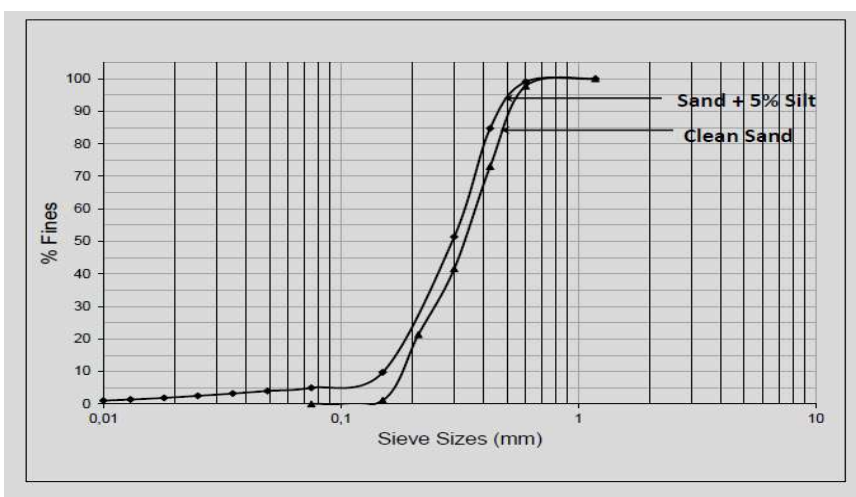

Figure 1 Typical gradation curve for clean sand with 5\% silt

\subsection{Shake Table Apparatus}

Shake Table test apparatus is specifically designed to conduct the tests for studying the criterion for initiation of liquefaction by simulating ground shaking during Earthquake. (Pathak et al, 2010). It comprises mainly of three main components, a vibrating platform of size 1000 $\mathrm{mm} \times 1000 \mathrm{~mm}$ made up of cast iron coated with silver paste, which vibrates with the soil model attached to it. A Control panel, the most important component of the shake table as it controls the frequency of the shaking has been given standard combinations of amplitude to produce the required acceleration. The vibrating platform is vibrated with the help of motor. The capacity of which is $3 \mathrm{H}$. P. with a three phase connection. Two types of soil models made of Perspex sheet have been manufactured. One is a square model with size 400 x 400 x $400 \mathrm{~mm}$ used by (Pathak et al, 2010) and other one is a rectangular model with size 800 × 600 × $400 \mathrm{~mm}$ ( Pathak et.al 2013) have effectively used these models to simulate the liquefaction for sand and carried out further parametric study. The apparatus arrangement for one dimensional sinusoidal excitation and model used is as shown in photograph 1.

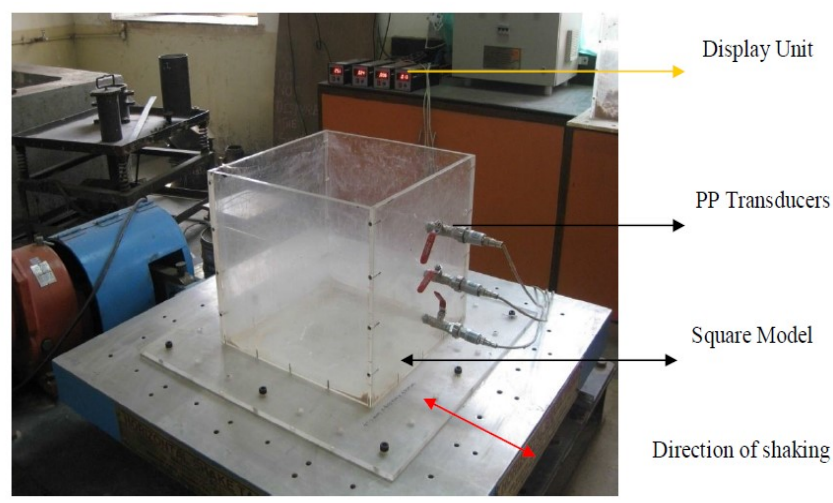

Photograph 1 Shake Table mounted with square model (size $400 \times 400 \times 400 \mathrm{~mm}$ ) 


\subsection{Instrumentation}

Three pore pressure transducers each of capacity 1 bar with the least count of $0.1 \mathrm{kPa}$ are attached to the shake table model at 3 levels, as shown in photograph 1. Measurement of displacement of shake table is carried out with Linear Variable Differential Transducer (LVDT) of capacity 50 $\mathrm{mm}$, with the least count of $0.1 \mathrm{~mm}$. Three pore pressure transducers and LVDT are connected to Data Acquisition system (DAQ) for recording the observations accurately. The necessary calibrations for these instruments are carried out using the charts for recording the readings for given time interval.

\subsection{Test Procedure}

Tests are conducted on all Sand-Silt mixtures as per the testing program. For various percentage of silt, sand and silt is mixed thoroughly until the uniform color is observed. Specific gravity, maximum and minimum dry densities of the mixture are obtained experimentally. From density values $\mathrm{e}_{\max }$ and $\mathrm{e}_{\min }$ are calculated. Actual voids ratio of the sand silt mixture is then evaluated to obtain the amount of water required to achieve a particular relative density. The calculated amount of sand-silt mixture is poured in the soil model by wet deposition method in 7 equal layers. Proper care has been taken to maintain the homogeneity of mixture. Amplitude and frequency of shake table is set on the control panel as per the maximum acceleration required which is verified with LVDT readings.

After filling the model the shake table apparatus is switched on, shaking starts at the required acceleration. The pore water pressure values at three levels are recorded through data acquisition system at the time interval of one second. Test is continued until pore pressures reach peak value and then start dissipating or remain constant as shown in photograph 2. At this instance, liquefaction is said to have occurred. The same procedure is used to conduct all the tests mentioned in the test program.

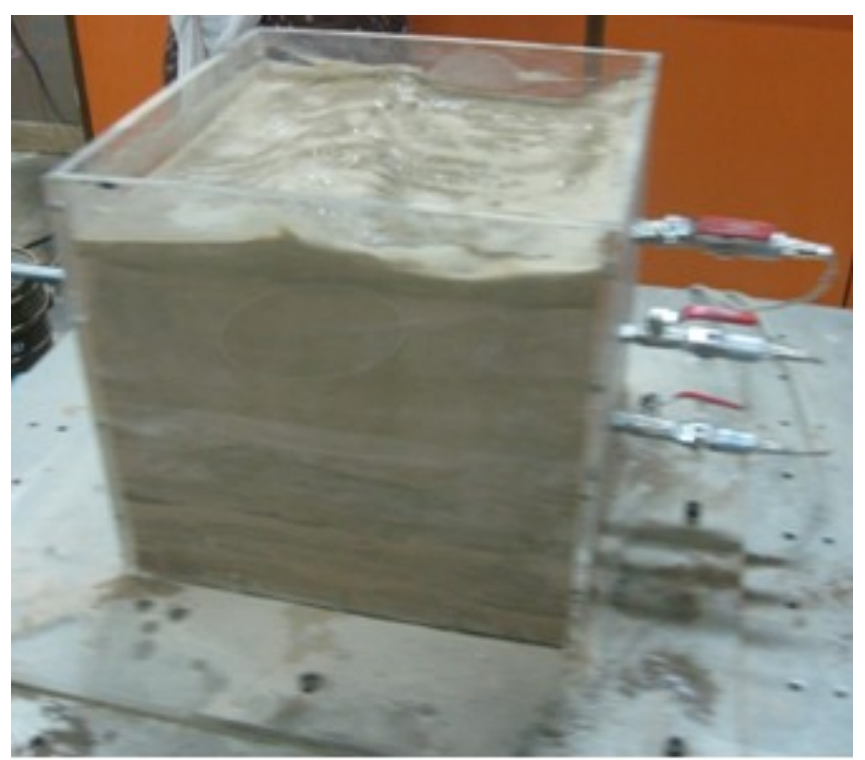

Photograph 2 Showing Model during Actual Testing

\section{DISCUSSION OF TEST RESULTS}

Effect of silt content on liquefaction resistance offered by sand-silt mixture is studied based on the excess pore pressure generated during shaking. The pore pressure values recorded during the test are used to compute the pore pressure parameter $\left(r_{u}\right)$ and cyclic stress ratio (CSR). Based on pore pressure-related criteria [Jiaer W.U. et.al], soil liquefaction has often been defined as the state at which the excess pore water pressure ratio $\left(r_{u}\right)$ equals 1.0 . This occurs when the pore water pressure increase $(\Delta u)$ becomes equal to the initial vertical effective overburden stress $\left[r_{u}=\Delta u / \sigma_{o}\right.$ $=1.0]$ in simple shear tests and in field studies, or when $\Delta \mathrm{u}$ equals the initial effective minor principal stress $\left[\mathrm{r}_{\mathrm{u}}=\right.$ $\left.\Delta \mathrm{u} / \sigma^{\prime}{ }_{3 \mathrm{c}}=1.0\right]$ in triaxial compression tests. However, this is not the only criteria for initiation of liquefaction; some other parameters should also be considered for studying the effect of fines. Cyclic stress ratio [CSR] is considered as an indication of number of cycles required for liquefaction. In the present study for assessing soil liquefaction, CSR is calculated using the Eq. (1) by Kramer.

$$
C S R=\frac{\tau_{a n g}}{\sigma_{v}^{\prime}}=0.65 \cdot \frac{a_{\max }}{g} \cdot \frac{\sigma_{v}}{\sigma_{v}^{\prime}} \cdot r_{d}
$$

Where,

$$
\begin{aligned}
\mathrm{a}_{\max } & =\text { maximum ground acceleration } \\
\sigma_{\mathrm{v}} & =\text { total stress } \\
\sigma_{\mathrm{v}} & =\text { effective stress } \\
\mathrm{g} & =\text { acceleration due to gravity }\left[9.81 \mathrm{~N} / \mathrm{m}^{2}\right] \\
\mathrm{r}_{\mathrm{d}} & =\text { reduction factor }
\end{aligned}
$$

The variation of these parameters with relative density and silt content are discussed in following sections.

\subsection{Effect Of Silt Content On Pore Pressure \\ Generation}

The pore pressure values are recorded at three levels by means of pore pressure transducers at top, middle and bottom of the soil model. The top layer remains liquefied during the entire test as the top transducer is connected at $0.05 \mathrm{~m}$ from the top surface of soil model where immediately after few seconds pore water comes out at the top and turbulence is seen in the top layer. Hence the results of the top transducer are not reported.

For all tests, it is observed that pore pressure gradually increases, reaches its maximum value and then starts dissipating continuously or remains constant till the end of the test. A typical variation of pore pressure versus time for relative density of $30 \%$ and $60 \%$ with $5 \%$ silt content for bottom transducer has been depicted in Figures 2 and 3 respectively. 


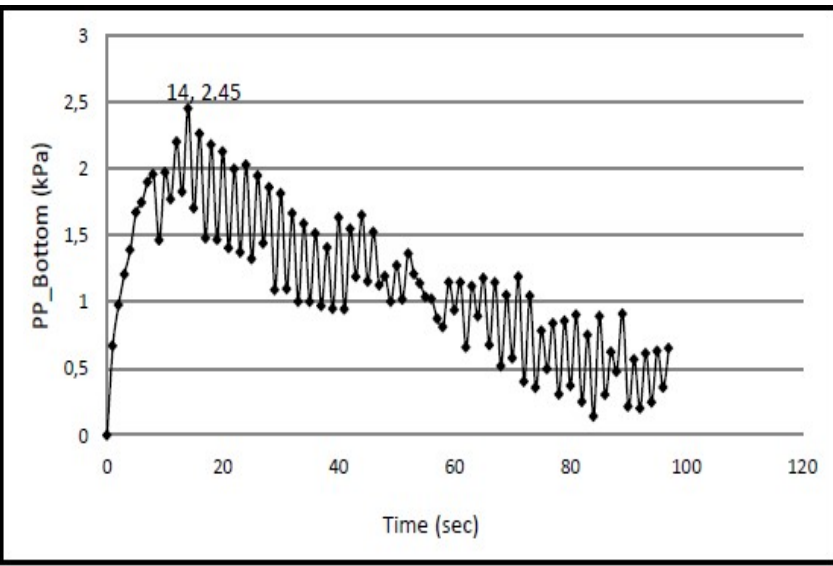

Figure 2 Pore Pressure Vs time for relative density of $30 \%$ and Silt 5\% for Bottom transducer

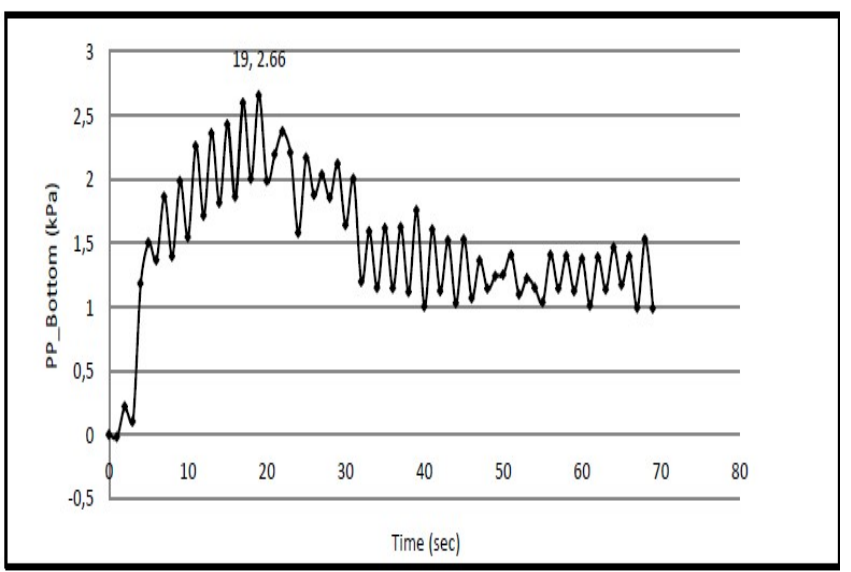

Figure 3 Pore Pressure Vs time for relative density of $60 \%$ and Silt 5\% for Bottom transducer

Figure 2 shows gradual increase in pore pressure until the peak value of magnitude $2.45 \mathrm{kPa}$ is reached at $14^{\text {th }}$ second. After attaining a peak value, it starts dissipating up to 72 second and then remains constant. However, for the test conducted at the relative density of $60 \%$ and silt content $5 \%$ (Figure 3.) maximum value of pore pressure attained is 2.66 $\mathrm{kPa}$ at $19^{\text {th }}$ second, after which it almost remained constant. In both the cases, the point at which maximum pore pressure is developed is considered as the point of initiation of liquefaction. From variation of pore pressure with the time at all the three transducers; it is observed that for all the test results, that liquefaction proceeds in the downward direction for the laboratory shake table apparatus in tune with Singh H.P. [4]. It is seen that the time required in attaining the maximum pore pressure increases with the increase in the relative density. The variation of pore pressure obtained for different silt contents indicates that time required for attaining peak pore pressure value increases as the silt content increases.

Figure 4 indicates variation of pore pressure with silt contents at different relative densities typically for bottom transducer. For a particular density, peak pore pressure values are found to increase marginally with the silt content. The same trend is observed for the middle transducer.

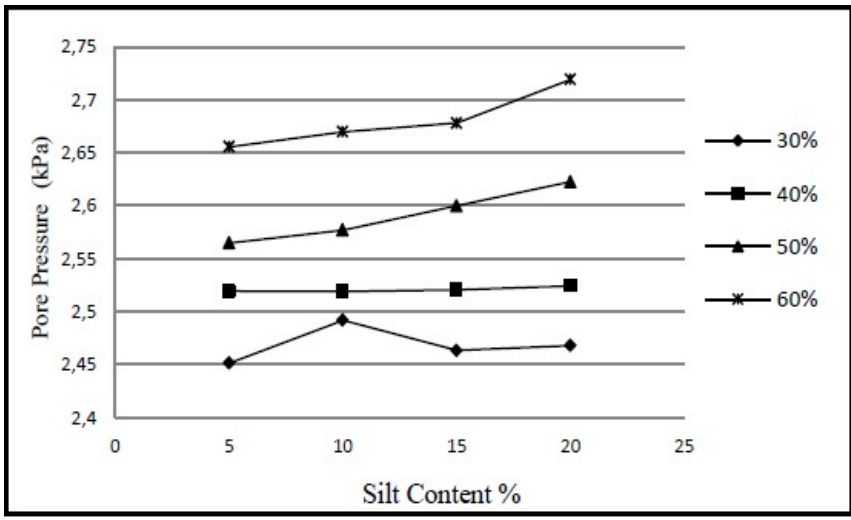

Figure 4 Variation of pore pressure with silt content for bottom transducer

\subsection{Variation of Pore Pressure Ratio (Ru) With Relative Density (Dr)}

Pore pressure ratio $\left(r_{u}\right)$, a non-dimensional parameter, defined as the ratio of excess pore pressure generated to the effective overburden pressure, has been evaluated corresponding to maximum value of pore pressure generated at the concerned pore pressure transducers. The increasing trend of $r_{u}$ with increase in relative density has been observed for bottom transducer as shown in figure 5 .

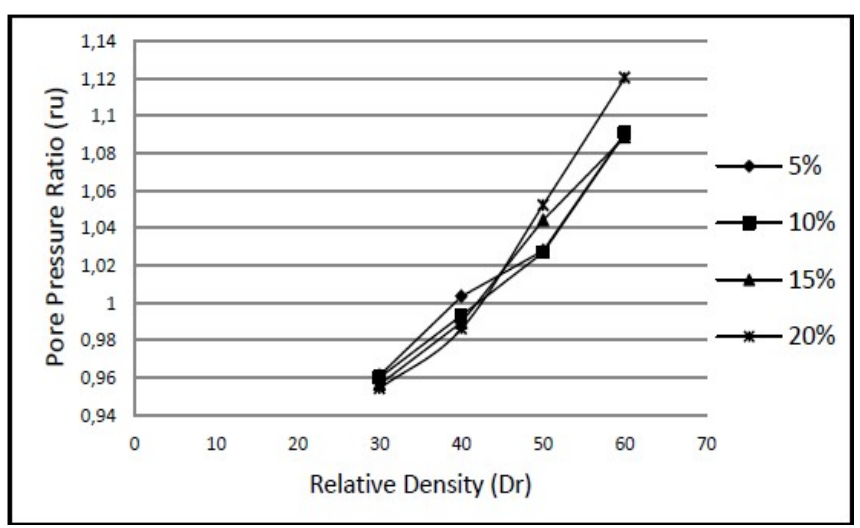

Figure 5 Variation of Pore Pressure Ratio $\left(r_{u}\right)$ Vs Relative Density (Dr) For Bottom Transducer

Maximum value of $r_{u}$ is observed at relative density of $60 \%$ and fines content of $20 \%$ which is of magnitude 1.12 for bottom transducer. At lower relative densities of $30 \%$ and $40 \%$ the variation in $r_{u}$ is marginal with the increase in silt content. At higher densities, increase in silt content increases $r_{u}$. Thus it can be infered that variation in silt content affects $r_{u}$ values mostly for higher densities (Dr $>40 \%$ ) for both middle and bottom transducers. At lower densities initiation of liquefaction has been observed for $r_{u}$ values of 0.95 to 0.99 . Thus these results indicate that liquefaction occurs at $r_{u}$ values even less than 1 especially for loose soils ( $\mathrm{Dr}<40 \%)$ as also reported by Behra (2005).

\subsection{Variation of CSR With Silt Content}

CSR values for all tests conducted in the present study are evaluated for both the transducers. Figure 6 depicts the variation of CSR values with silt content for bottom 
transducer for all relative densities.

For lower relative density values $(\mathrm{Dr}<40 \%)$ with the increase in silt percentage CSR almost remains somewhat constant. However, for the relative density values greater than $40 \%$, CSR decreases with increase in fines content. This shows that higher silt contents at higher densities offer better resistance to liquefaction.

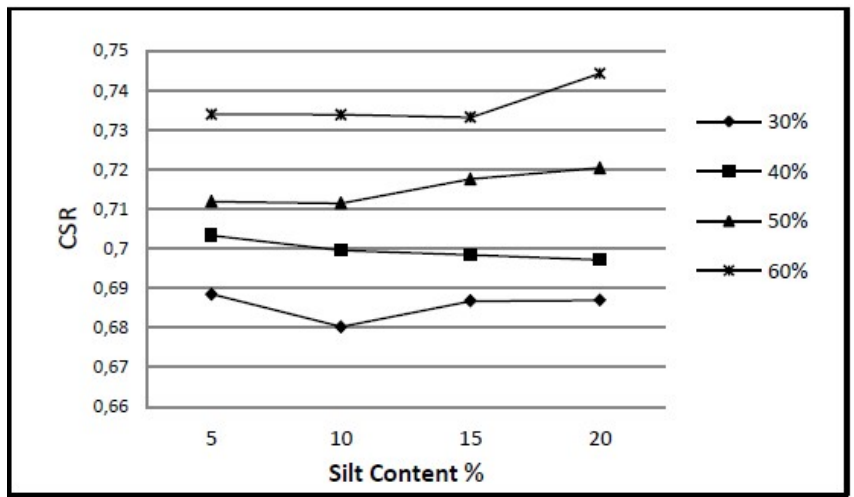

Figure 6 Variation of CSR with Silt Content for Bottom transducer

Table 2 Field Data for "Yes" liquefaction cases

\begin{tabular}{|l|l|l|l|l|l|l|l|}
\hline Site & $D_{50}(\mathrm{~mm})$ & Fines Content (\%) & $\begin{array}{l}\text { C.P.T.q } \\
(\mathrm{MPa})\end{array}$ & $\mathrm{a}_{\max }$ & Test $\mathrm{a}_{\max }$ & \multicolumn{2}{l|}{ CSR } \\
\cline { 3 - 9 } & & & & & & & \\
\hline Imperial Valley & 0.11 & $15-20$ & 2.56 & $0.60 \mathrm{~g}$ & $0.6 \mathrm{~g}$ & 0.52 & 0.5524 \\
\hline Port of Oakland & 0.25 & $0-5$ & 12.38 & $0.29 \mathrm{~g}$ & $0.29 \mathrm{~g}$ & 0.25 & 0.4785 \\
\hline Loma Prieta & 0.27 & 7 & 5.10 & $0.29 \mathrm{~g}$ & $0.3 \mathrm{~g}$ & 0.26 & 0.3879 \\
\hline
\end{tabular}

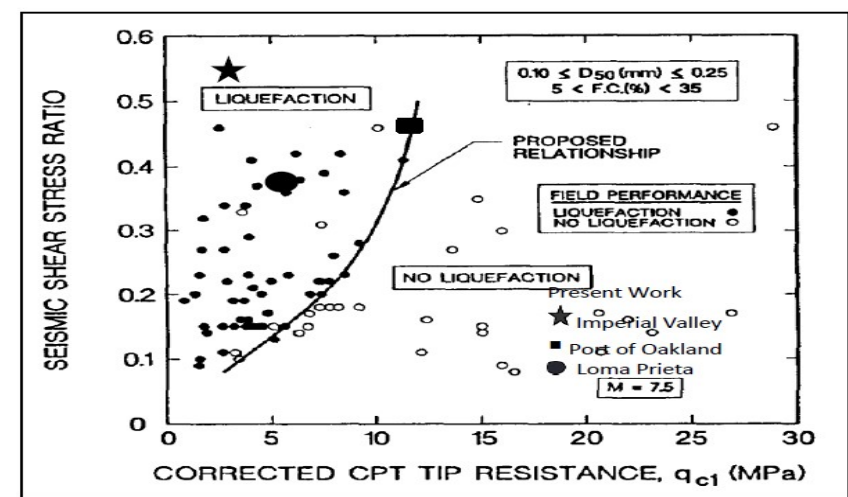

Figure 8 Graph showing "YES" and "NO" liquefaction zone based on seismic shear stress ratio and CPT based relationship

\subsection{Comparison with Other Tests}

Polito and Martin (2001) conducted cyclic triaxial tests on sand-silt mixture. The results of their study are shown in the figure 7. The results from the present experiments are superimposed on the graph of CSR Vs Relative density for comparison. The trend of the curve is observed to be similar to some extent similar as obtained by Polito and Martin (2001), but the values obtained in the present study are on higher side than those obtained by the researchers, the reason could be the characteristics of the sand and type of test used. Figure 7 shows the variation of CSR with relative density typically for $5 \%$ silt content. For $10 \%$ and $15 \%$ fines content the same trend of CSR variation with the relative density is observed.

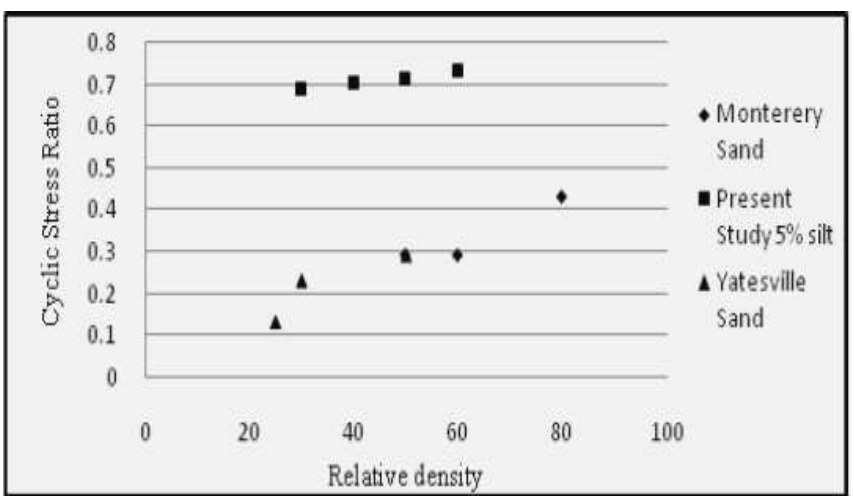

Figure 7 CSR Vs Relative Density For 5\% silt content

The present study results when compared with earlier researchers showed higher values of pore pressure for same silt content. It could be due to different properties of sand and silt used during experimentation. Further, as the type of test conducted is different, values are on higher side though the overall trend is the same. Thus, it can be inferred that quantitative effect of silt content on liquefaction behavior of sand-silt mixture is soil specific as well as test specific.

\subsection{Comparison with Field Data}

Out of 19 tests 3 site specific tests are conducted. The data from field have been selected based on $\mathrm{D}_{50}$ size, fines content and acceleration values of "Yes" liquefaction cases. The details of selected points (Stark \&Olson 1995) are as shown in table 2 .

Using the $\mathrm{q}_{\mathrm{c} 1}$ and $\mathrm{D}_{50}$ from the field data for these points, the relative density values are computed. The soil sample with the same fines content $\&$ relative density has been prepared in the lab for each of these data points and tested for the 
same $a_{\max }$. CSR values for these three points have been obtained from present lab test and then superimposed on the curve given by Stark and Olson (1995) as shown in figure 8 which demarcates "YES" and "NO" zones of liquefaction. It can be seen from the figure that all three points where liquefaction actually occurred in field lay in "YES" zone of liquefaction. This clearly shows that the shake table test used in the present study simulates the field conditions reasonably well in respect of occurrence of liquefaction.

\section{CONCLUSIONS}

The time required in attaining the maximum pore pressure increases with the increase in the relative density. The variation of pore pressure obtained for different silt contents indicates that time required for attaining peak pore pressure value increases as the silt content increases.

At lower densities initiation of liquefaction has been observed for $r_{u}$ values of 0.95 to 0.99 . Thus these results indicate that liquefaction occurs at $r_{u}$ values even less than 1 especially for loose soils ( $\mathrm{Dr}<40 \%$ ).

For lower relative density values $(\mathrm{Dr}<40 \%)$ with the increase in silt percentage CSR almost remains somewhat constant. However, for the relative density values greater than $40 \%$, CSR decreases with increase in fines content. This shows that higher silt contents at higher densities offer better resistance to liquefaction

The results of present investigation when compared with those of triaxial tests conducted by other researchers, trend of variation of CSR with relative density is found to be similar for all silt contents used in this work. The quantitative effect of silt content on liquefaction behavior of sand-silt mixture is soil specific as well as test specific.

Further, the locations where liquefaction has occurred in field when checked with present shake table tests, they are found to lie in the 'yes' zone of liquefaction. Thus it can be concluded that for the range of silt content studied in the present work, for higher silt content liquefaction occurrence is delayed. Field test results indicate that shake table test can better simulate field conditions for assessing initiation of liquefaction.

\section{REFERENCES}

[1]. Behra K.C., and Swami Saran, and Mittal R.K. (2005). "Liquefaction Studies on Sand and Sand-Silt Mixture." IGC-2005, 397-400.

[2]. Carraro, J. A.H, and Bandini, P., and Salgado, R. (2003) "Liquefaction Resistance of Clean and Nonplastic Silty Sands Based on Cone Penetration Resistance.”ASCE J. Geotech. Geoenviron.Eng. 129 (11), 965-976.

[3]. Dr. S. R. Pathak, M. P. Kshirsagar, M. S. Joshi, (2013) "Liquefaction Triggering Criterion Using Shake Table Test"; International Journal of Engineering and Technology ISSN :0975-4024 Vol. 5 No 5 Oct-Nov $2013,4439-4449$
[4]. Fletcher M. Wood, Yammamuro, Jerry A., and Lade, Poul V., (2008). "Effect of Depositional Method on Undrained Response of Silty Sand.” Can. Geotech. J. 45:1525-1537.

[5]. Iwasaki, T., and Tatsuoka, F. (1977). "Effects of grain size and grading on dynamic shear moduli of sands." Soils Found. 17(3), 19-35.

[6]. Jiaer W.U., A.M. Kammerer, M.F. Riemer, R.B. Seed and J.M. Pestana; "Laboratory Study of Liquefaction Triggering Criteria", 13th World Conference on Earthquake Engineering, Vancouver, B.C., Canada, Paper No. 2580, 2004.

[7]. Kramer S.L.; Geotechnical Earthquake Engineering, published by Dorling Kindersley [India] Pvt. Ltd. licensees of Pearson Education in South Asia,1996.

[8]. Maheshwari, B.K. and Patel, A.K. (2010). Effects of Non-Plastic Silts on Liquefaction Potential of Solani Sand. Journal of Geotech. Geol Eng. 28, 559-566.

[9]. Ning Liu, S.M.ASCE1; and James, K.M., and Hon. M. (2006). "Influence of Non plastic Fines on Shear Wave Velocity-Based Assessment of Liquefaction.", ASCE J. Geotech. Geoenviron. Eng., 132(9), 10911097.

[10]. Pathak, S. R., Dalvi, R. S., and Katdare, A. D. (2010), "Earhquake Induced Liquefaction Using Shake Table Test", Conference on Recent Advances in Geotechnical Earthquake Engineering and Soil Dynamics.

[11]. Polito, C. P. (1999). "The effects of nonplastic and plastic fines on the liquefaction of sandy soils" $\mathrm{PhD}$ thesis, Virginia Polytechnic Institute and State University, Blacksburg.

[12]. Polito, C.P., and Martin, J. R. (2001). "Effects of Nonplastic Fines on the Liquefaction Resistance" ASCE J. Geotech. Geoenviron. Eng., 127(5), 408415.

[13]. Prasad, T. G., Towhata, S. K., Chandradhara, L., and Nanjundaswamy, P., (2004) "Shaking Table Tests In Earthquake Geotechnical Engineering." Current Science, 87(10) 1398-1404.

[14]. Singh H. P., Maheshwari B. K., Saran S; "Liquefaction Behavior of the Solani Sand using Small Shake Table", The 12th International Conference of International Association for Computer Methods and Advances in Geomechanics [IACMAG], pp. 2797-2803,2008.

[15]. Yamamuro, J.A., and Covert, K.M. (2001). "Monotonic and Cyclic Liquefaction of Very Loose Sands with High Silt Content." ASCE J. Geotech. Geoenviron. Eng., 127(4), 314-324.

[16]. Zhou, Y.G., and Chen, Y. M. (2007). "Laboratory Investigation on Assessing Liquefaction Resistance of Sandy Soils by Shear Wave Velocity." ASCE J. Geotech. Geoenviron. Eng., 133(10), 959-972. 